\title{
Sub-grid-scale differences between individuals influence simulated phytoplankton production and biomass in a shelf-sea system
}

\author{
Niall Broekhuizen ${ }^{1, *}$, John Oldman ${ }^{1}$, John Zeldis ${ }^{2}$ \\ ${ }^{1}$ National Institute of Water \& Atmospheric Research Ltd., PO Box 11-115, Gate 10, Silverdale Road, Hamilton 2001, New Zealand \\ ${ }^{2}$ National Institute of Water \& Atmospheric Research Ltd., PO Box 8602, 10 Kyle Street, Riccarton, Christchurch 8001, New Zealand
}

\begin{abstract}
In reality, individuals differ from one another. Some of this can be attributed to genetic differences, but much is due to environmental effects. Even neighbouring cells will have differing histories and may be in differing physiological condition in consequence. Many of the processes governing cell-growth are non-linear functions of the cell's physiological state. This, together with the possibility that each cell will be in a unique physiological state, implies that it is not possible reliably to infer the population-level growth rate from the product of population abundance and an individual growth-rate derived on the basis of the average physiological characteristics of the local population. Unfortunately, this is precisely the assumption that is implicit in the vast majority of phytoplankton models - which take no account of local-scale physiological structure in the phytoplankton population. Here, we present an individual-based population model of phytoplankton dynamics. This model utilises the Lagrangian Ensemble method to take account of local-scale physiological structure in the population. We make comparisons of the predictions of this model when run as a truly individual-based model or in a manner mimicking a model having no representation of local-scale population physiological structure. The results suggest that, under realistic environmental conditions, individuals in close proximity to one another can indeed be in substantially different physiological condition. More importantly, failure to take proper account of this variability results in differences of more than $30 \%$ between the predictions of standing crop and productivity made by the structured-model descriptions of the same underlying biology.
\end{abstract}

KEY WORDS: Lagrangian Ensemble method • Physiologically structured population models . Nutrient-phytoplankton dynamics $\cdot$ New Zealand continental shelf

\section{INTRODUCTION}

Within nutrient-phytoplankton models, the phytoplankton populations are usually described only in terms of some measure(s) of their total biomass. If these models include an explicit spatial component, this is usually framed in Eulerian terms: the spatial domain is sub-divided into a grid of abutting 'boxes' or 'controlvolumes', and mass balance equations are written for the various ecosystem components within each control-volume. Adjacent control-volumes are coupled through exchange of material across their shared interface (driven by advection and dispersion). The Euler- ian approach is comparatively simple to encode, but has 2 important drawbacks. Firstly, there are wellknown difficulties associated with solving advection equations on an Eulerian grid (Chapra 1997). These are particularly evident where there are strong frontal features or areas where the prevailing currents run transverse to the grid-axis and can lead to seriously erroneous results when the grid resolution is too coarse relative to the ratio of transport speed to population growth rate (Broström 2002). Secondly, it is not easy to maintain a record of any sub-(spatial)-grid-scale variation in the physiological state of the individual cells which comprise the local population. Indeed, Eulerian 
models usually only carry the first moment (mean) for each characteristic of the control-volume's population-we will refer to these as 'simple Eulerian models'. The implicit assumption of simple Eulerian models is that the responses of the underlying individuals of the population can be adequately inferred from the (local) population mean characteristics. In effect, all the individuals are assumed to be in an identical physiological state and, by implication, to exchange properties with one another infinitely fast.

The assumption that individuals are identical may be a serious limitation because many biological processes are highly non-linear; therefore, the true total-population rate arising from the cumulative activities of each individual-is not equivalent to the rate inferred from the product of number of individuals and the rate dictated by the local population-average physiological state. Two means of incorporating more information on the local-scale physiological structure of a population have been presented: the extended Eulerian method (Janowitz \& Kamykowski 1999) and the Lagrangian Ensemble method (Woods \& Onken 1982, Woods \& Barkmann 1993). In the extended Eulerian method, the control-volume approach is extended beyond 3 dimensions to include 1 or more axes of physiological variability in addition to the spatial axes. This implies that several sub-classes of each functional group can be present within each (spatial) control-volume. The demographics of each sub-class are influenced not only by its local (in geographic space) growthdynamics and spatial exchange fluxes, but also by movement of individuals between the sub-classes within the spatial control-volume. In the Lagrangian Ensemble method, the phytoplankton population is not discretised into spatial units, but rather into units based upon shared histories and hence, common physiological status. Specifically, the population is partitioned amongst numerous 'particles' (henceforth, 'ensembles'). Each ensemble is representative of numerous (usually many billions) of individual cells. We will adopt the term 'ensemble size' to denote the number of individual cells of which the ensemble is representative, and 'clonal cell' to refer to these cells collectively. Each ensemble represents a weighted (by the number of cells which share the clonal cell's history) sample from the true population. Particle transport is driven by a combination of water-movementdriven advection, turbulent dispersion and intrinsic 'swimming' behaviour. In the terminology of Brickman \& Smith (2002), particle movement is simulated using a 'random displacement model'.

The important distinction between the Lagrangian Ensemble and Eulerian approaches is that, in the former, advection and dispersion (whether in space or physiological dimensions) drive the movements of individual ensembles rather than exchange of properties between control-volumes. Thus, there is no implicit exchange of properties between the many individuals that comprise a control-volume's population. Equally important, the Lagrangian Ensemble method is immune to the numerical problems associated with solving advective equations using a grid-based scheme. The Lagrangian Ensemble approach is also well suited to the individual-based modelling paradigm. This paradigm has gained credence amongst many experimental biologists because of its intuitive appeal, and the ease with which greater physiological/behavioural detail can be incorporated into such models.

Relative to the simple Eulerian approach, the Lagrangian Ensemble approach has some substantial disadvantages. Firstly, great care must be taken when there are spatial variations in the magnitude of dispersive mixing (Visser 1997, Brickman \& Smith 2002) and where there is strong curvature in the current fields. Indeed, Brickman \& Smith (2002) argue that these problems may be insuperable if the turbulence field is not resolved sufficiently finely. Secondly, the Lagrangian Ensemble method is much more computationally demanding. This is because: (1) within each control-volume, many ensembles are required if one is to make credible claims that dispersive transport and the probability density functions (PDFs) of the physiological characteristics are being adequately represented; and (2) in addition to the state-variables used for the nearest-equivalent Eulerian model, it requires 3 additional state variables $(x, y, z$ locations $)$ per ensemble.

Within this paper, our aims are to make a comparison of the primary production simulated using different variants of a Lagrangian Ensemble model of New Zealand's NE continental shelf. In one group of variants, the model explicitly uses information regarding the PDF of the local population's physiological structure. In the second, individuals are forced to behave in the manner dictated by the local mean physiological state, thereby mimicking many of the properties of the simple Eulerian method. We make the comparison for 2 contrasting types of phytoplankton: diatoms (require $\mathrm{N}$ and $\mathrm{Si}$ for growth, limited motility, but fast growth) and dinoflagellates (require only $\mathrm{N}$ for growth, greater motility, but slow growth). Our spatial domain encompasses a wide variety of habitats, i.e. deep, relatively clear, shelf-break waters through to shallow $(<10 \mathrm{~m})$, turbid estuarine waters, and both upwelling and downwelling conditions. Our aims are to determine the magnitude of local-scale between individual variability, and the dynamical significance of such variability.

Lagrangian models of phytoplankton dynamics have been used in several studies (e.g. Kamykowski et al. 1994, Barkmann \& Woods 1996, Lizon et al. 1998, 
Broekhuizen 1999), but to the best of our knowledge, only McGillicuddy (1995) has made a comparison between the results stemming from Eulerian and Lagrangian variants of the same underlying biological model. McGillicuddy applied both methodologies with 2 different models of photoinhibition. He found that the mean phytoplankton weight-specific daily growth rate differed by no more than $5 \%$ when vertical mixing was slow, but when vertical mixing was rapid and photo-adaptation was slow, the daily growth rates predicted using the 2 different numerical algorithms differed by ca. $20 \%$. Using their extended Eulerian method, Janowitz \& Kamykowsi (1999) found that substantial local-scale between-individual variations arose. Thus, it is probable that their model would also predict dynamics which differ from those of a simple Eulerian model.

The NE shelf of New Zealand's North Island comprises 3 distinct areas (see Fig. 1): a comparatively narrow northern region $(<200 \mathrm{~km}$ wide; the 'open coastal' region) which opens directly onto the shelfbreak, the Hauraki Gulf (a large, shallow embayment bounded by the open shelf waters to the north), Great Barrier Island/Coromandel Peninsula to the east and the Firth of Thames to the south. The Firth of Thames

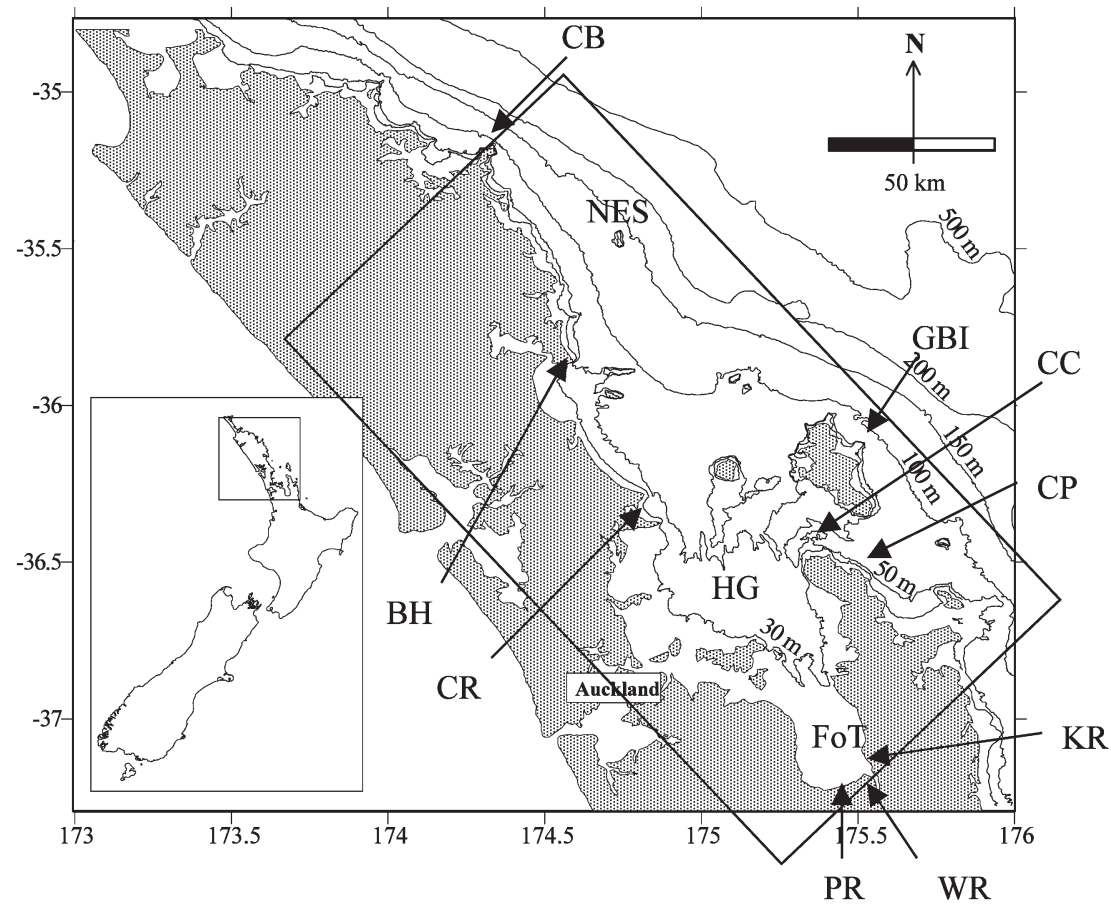

Fig. 1. Sites on the NE coast of North Island, New Zealand. The rectangle superimposed upon the main map represents the approximate horizontal extent of the model's domain. FoT: Firth of Thames; HG: Hauraki Gulf; NES: northeast shelf; GBI: Great Barrier Island; CB: Cape Brett; BH: Bream Head; CR: Cape Rodney; CP: Coromandel peninsula; CC: Colville channel; PR: Piako river, WR: Waihou river; KR: Kaueranga river is an estuarine system. The major riverine inputs to the system stem from the Piako and Waihou rivers (both draining pastoral land and carrying high nutrient and sediment loads) and the Kaueranga river (draining native lowland forest with correspondingly reduced nutrient and sediment load). All 3 rivers drain into the southernmost regions of the Firth of Thames.

H. Chang et al. (unpubl.) and J. Zeldis et al. (unpubl.) summarise the physical and biological characteristics of the NE shelf region. During the spring, prevailing westerlies and north-westerlies drive surface, opencoastal waters offshore and cause localised upwelling of deep, nutrient-rich oceanic waters onto the nearshore areas of the open coastal shelf. During the summer, easterly winds tend to predominate. This reverses the surface water circulation, such that nutrientdepleted surface shelf waters downwell. The Firth of Thames and Hauraki Gulf regions are also strongly influenced by estuarine circulation patterns stemming from the riverine inputs into the Firth of Thames. Thus, the Firth and Gulf are frequently stratified and in combination with benthic remineralisation, this results in a persistent near-bed nitrate maximum underlying an oligotrophic mixed layer. The near-bed maximum, combined with riverine inputs deriving from the Firth of Thames, results in production within the Gulf being less sporadic than the (upwelling-) event-driven production of the open shelf waters to the north.

There are marked seasonal changes in the nature of the phytoplankton community of the open coastal and Gulf waters-probably driven by the seasonal changes in physico-chemical conditions. During spring, the inner-shelf region of the open coastal waters supports a high biomass community of large, chain-forming diatoms. As N becomes depleted, this gives way to a community of smaller diatom species and eventually to a mixed community of small diatoms, dinoflagellates, small phytoflagellates and picophytoplankton late in the summer. Farther offshore, the (relatively nutrient-poor) outer shelf waters harbour lower phytoplankton biomass dominated by small, motile taxa throughout the spring and summer. Within the Hauraki Gulf, the phytoplankton community is dominated by larger, autotrophic dinoflagellates in spring, but later in the year these are replaced by smaller autotrophic and heterotrophic dinoflagellates, nanoflagellates and picophytoplankton. 


\section{METHODS}

Model summary. Our model is a 3-dimensional extension of the one presented in Broekhuizen (1999). Briefly, we include state variables for: local dissolved inorganic nitrogen (DIN), local dissolved reactive silicon (DRSi), local C, N and Si masses of organic detritus (POMC, POMN, POMSi); and for each of diatoms and dinoflagellates: abundance of cells, and $\mathrm{C}, \mathrm{N}$ and $\mathrm{Si}$ biomass. Nutrients and organic detritus are simulated using the Eulerian approach. We use the Lagrangian Ensemble method to describe the phytoplankton populations (see below for a description of how this method is used to mimic the simple-Eulerian approach).

The (default) phytoplankton model makes a distinction between cellular biomass and cell numbers. We will refer to this as the biomass-and-numbers Lagrangian Ensemble (B\#-LE) model. Cell division is assumed to take place when the cell surpasses a prescribed C mass $\left(W_{\text {fission}}, \mathrm{mgC} \mathrm{cell}^{-1}\right)$. Each daughter cell is assumed to inherit half the mass of the parent. Starvation-death occurs should the cell's $C$ mass fall below a prescribed minimum $\left(W_{\text {starve }}<0.5 W_{\text {fission }}\right)$. In addition to discrete birth and death events related to a cell's physiological state, the phytoplankton populations are also assumed to suffer 'background' mortality (grazing and bacterial/viral lysis). This is implemented as a 1st-order loss; note, this is a continuous loss, cf. discrete changes due to birth and starvation. The model of cellular growth incorporates terms reflecting quota-dependent regulation of the rates of excretion, photosynthesis and nutrient uptake, but lacks any photo-inhibition terms.

Ensemble-specific rates of photosynthesis and nutrient uptake etc. are calculated from the product of ensemble-C biomass and the clonal cell's mass-specific photosynthetic rate as well as uptake rates etc. Local (to the ensemble) environmental conditions (orthogonal currents, temperature, light, nutrient concentrations etc.) are interpolated from the corresponding Eulerian field (in the vertical dimension only, except for orthogonal current vectors, which are interpolated in the $x, y$ or $z$ directions as appropriate). Within each control-volume, we assume that the 'red' and 'green' light fractions decay exponentially (Taylor et al. 1991; the colour-specific attenuation coefficients are calculated as the sums of background and phytoplankton-C terms); for all other characteristics, we use linear interpolation.

The light-dependence of photosynthesis is described using the Smith-formulation (Smith 1936); however, the realised photosynthetic rate becomes suppressed below the light-dependent rate as the nutrient quota (dinoflagellates, $\mathrm{N}: \mathrm{C}_{i}$ diatoms, $\mathrm{N}: \mathrm{C}$ or $\mathrm{Si}: \mathrm{C}$ ) ratio approaches prescribed minima. Similarly, the nutrient uptake rate is dependent upon both the external nutrient concentration (Michaelis-Menten function) and the internal $\mathrm{N}: \mathrm{C}(\mathrm{Si}: \mathrm{C})$ ratio of the cell.

Dinoflagellates are assumed to swim upward $(15 \mathrm{~m}$ $\mathrm{d}^{-1}$ ) unless their $\mathrm{N}: \mathrm{C}$ quota becomes sufficiently depleted. When this occurs, they switch to swimming downwards. They continue swimming downwards until (1) their stores are sufficiently replenished (a second, higher $\mathrm{N}: \mathrm{C}$ threshold); (2) the (external) nutrientconcentration dependent nutrient-uptake rate exceeds $90 \%$ of the maximum nutrient uptake rate; or (3) the cell comes within $1 \mathrm{~m}$ of the sea-floor. Under Condition 1 , the cells will once again begin to swim upwards, under Conditions 2 and 3, they will endeavour to remain (vertically) stationary. Diatoms cannot swim, but they are able to regulate their buoyancy (Smayda 1970, Villareal 1992). We assume that their buoyancy behaviour is analogous to the swimming behaviour of the dinoflagellates: they endeavour to ascend (i.e. are neutrally buoyant) when nutrient replete $(\mathrm{N}$ and $\mathrm{Si})$, but sink $\left(5 \mathrm{~m} \mathrm{~d}^{-1}\right)$ when they are N- or Si-stressed. We impose a reflecting bottom boundary condition for all components of the ecosystem.

The $\mathrm{C}$ and $\mathrm{N}$ fractions of organic detritus are assumed to decay into inorganic forms at rates of $5 \%$ $\mathrm{d}^{-1}$ (Enríquez et al. 1993, Verity et al. 2000). Detrital Si is assumed to decay at a much lower, temperaturedependent rate $\left(\sim 0.0006 \mathrm{~d}^{-1}\right.$ at $20^{\circ} \mathrm{C}$; Kamatani 1982, Tréguer et al. 1989).

We wish to determine whether a model lacking any representation of local-scale physiological structure (thus, with implicit infinitely fast exchange of materials between phytoplankters within each control-volume) yields results which are substantially different from the more biologically rigorous structured approach. The simple Eulerian approach introduces additional, unavoidable, false exchanges between control-volumes. Since we wish to avoid these, we will force our Lagrangian model to behave as a close analogue of a simple Eulerian formulation. Specifically, before beginning each time-step, we bring the $\mathrm{C}, \mathrm{N}$ (and $\mathrm{Si}$ ) cellular weights of all corresponding (by taxon and cell-quota-dependent swimming direction) ensembles within each control-volume into equilibrium with one another. We emphasise that we are equilibrating only the cell masses and not the number of cells associated with each ensemble. This equilibration process provides a close mimic to the instantaneous intra-controlvolume mixing implicit within simple Eulerian models. In particular, it erases all the information regarding the higher moments of the probability distributions of cell physiology. It entirely avoids any numerical dispersion between control-volumes. It also precludes any false intra-control-volume dispersion of cells, but (as required) it does imply some false intra-control-volume 
dispersion of cellular mass. This variant of the model retains the distinction between population abundance (cell numbers) and population biomass. We will refer to this form of the model as the 'biomass-and-numbers Lagrangian as Eulerian' (B\#-LAE) variant.

We will show that the B\#-LE and B\#-LAE model variants yield results which differ substantially, although they share the same qualitative behaviour. The differences must stem from the combination of (1) betweenindividual variations within each control-volume; and (2) false transfer of cellular mass in the LAE formulation and 1 or more of non-linearities in (i) the quotadependence of photosynthesis and nutrient uptake, (ii) the hysteretic relationships between cell quota and 'swimming' direction, and (iii) the relationships between cell-fission or starvation and cell weight. The majority of Eulerian nutrient-phytoplankton models are formulated as biomass-only models. Such models cannot distinguish between cellular growth (weight gain or loss) and population growth (or loss). If the differences between the results of our B\#-LE and B\#-LAE variants arise primarily as a result of the non-linearity between cell weight and cell fission or starvation, it is probable that the results of Lagrangian and Lagrangian-as-Eulerian biomass-only simulations would be more similar than are our B\#-LE and B\#-LAE. We explore this possibility by reformulating our biomassand-numbers model so that it becomes a biomass-only model. Specifically, net cellular growth $\left(g_{\text {cell }}, \mathrm{mgC}\right.$ cell $^{-1} \mathrm{~d}^{-1}$ ) is assumed to translate instantaneously into population growth $\left(c_{\text {net }}\right.$, cells cell $\left.{ }^{-1} \mathrm{~d}^{-1}\right)$ in a manner that implies that the average cell weight remains constant (at $0.75 W_{\text {fission }}$ ):

$$
C_{\text {net }}=\frac{g_{\text {cell }}}{0.75 W_{\text {fisson }}}
$$

When $0<g_{\text {cell }}, c_{\text {net }}$ represents a per capita rate of cell births. When $0 \geq g_{\text {cell }}, c_{\text {net }}$ represents a per capita cell death rate. We emphasise the assumption that individuals can starve down to 0 weight. This assumption is implicit in standard biomass-only models, but it does differ from the (more realistic) assumption in our biomass-and-numbers variants of the model. We will use the acronymn $\mathrm{BO}$ to refer to this biomass-only formulation. Using the BO-variant of the model, we repeat the Lagrangian Ensemble (BO-LE) and Lagrangian-as-Eulerian (BO-LAE) simulations in order to determine the relative importance of the nonlinearities associated with cell quota and cell size.

Numerical solution. The differential equations were solved using a 2nd-order Runge-Kutta algorithm with a time-step of $15 \mathrm{~min}$ (sufficiently fine to obtain results which are, to graphical accuracy, time-step-insensitive). After each time-step, a check was made to determine whether any discrete events (e.g. cell-weight- or cell- quota-dependent events and passage of a ensemble from one control-volume into another) have taken place during the time-step. Accrued events were processed in chronological order. A more rigorous numerical treatment would require that we revert to the beginning of the time-step, integrate only as far as the first event-time, process this event and then recommence the integration. Fortunately, to graphical accuracy, the simulation results are insensitive to this stricture.

As a result of the finite spatio-temporal resolution of (1) the time-series of currents, (2) bathymetry and (3) integration time-step, it is possible for ensembles to pass below the sea-floor during a time-step. By default, we correct this by reflecting the ensemble off the seafloor; however, if the ensemble has also passed into a new water-column, we first check to determine whether it would have been below the sea-floor with respect to the water-column in which it started the time-step. If it is also below the sea-floor by this criterion, it is reflected off the new water-column's seafloor. If not, we place the ensemble within the new water-column at a depth corresponding to its sigmacoordinate with respect to the original water-column, i.e. we assume that the sea-floor crossing reflects inadequate spatio-temporal resolution in the bathymetry/ currents.

Occasionally, vertical dispersion rates are large enough to violate the stability conditions associated with solution of advection/dispersion equations on a Eulerian grid. In such situations, we use an appropriately reduced vertical dispersion coefficient when solving the Eulerian (cf. Lagrangian) balance equations over the time-step, but subsequently equilibrate the control-volumes which border the 'offending' interface before taking the next time-step.

Ideally, one would carry 1 ensemble for each (true) algal cell within the population. In practice, this is beyond the scope of current and foreseeable computational power. Thus, each ensemble must be considered to be representative of numerous individual algal cells. It is also not practicable to generate a new ensemble (for 1 of the 2 'daughter' ensembles) upon each division of a clonal cell. Rather, in general, we allow the population associated with the ensemble to double. Consequently, where there is variation in the cellular growth rates associated with different ensembles, substantial variations in the 'size' of each ensemble may accrue. Unfortunately, in the model, it is the ensembles (rather than the underlying individual algal cells) that are transported. Where nearby (relative to the scale of dispersive mixing) ensembles differ in size, dispersion could introduce an erroneous net transport of cells and biomass. Where flows are diverging, subsequent dispersion may not have the chance to reverse the tempo- 
rary imbalance. We therefore endeavour to ensure that nearby ensembles remain of similar size by allowing ensemble fission to accompany cell fission only if: (1) the 'parent' ensemble is of size greater than twice the meso-scale average; and (2) the algal-class-specific number of ensembles within the domain is below a user-defined threshold, reflecting ultimate run-time and memory constraints. We define the meso-scale to be (1) horizontally \pm 1 Eulerian control-volume width; and (2) vertically sea-surface to mixed-layer depth (for ensembles within the mixed-layer) or mixed-layer depth to sea-floor (for ensembles below the mixedlayer depth). Mixed-layer depth is calculated using the method of Kara et al. (2000).

Given our view of each ensemble as being representative of a large number of individual algal cells, each sharing a common history (and hence, physiological state), there is an argument that the cell count associated with each ensemble should not take fractional values less than 1, and that ensembles should be eliminated, i.e. the associated population be deemed to have become extinct, when the cell count does fall below 1. The counter-argument is that the time-toextinction then becomes dependent upon the number of ensembles across which a given total population is sub-divided, assuming the 'background' mortality to be 1st-order as in our model. This undesirable characteristic follows because the final 'extinction' event violates the Poisson process assumptions implicit in the background mortality term. Fortunately, although we have adopted the 1-cell extinction criterion, no such events occur in our simulations.

For inorganic nutrients and organic detritus, we use central differences to derive the dispersive fluxes between adjacent control-volumes, and the van Leer Scheme I (van Leer 1977, Hourdin \& Armengaud 1999) to derive the advective fluxes. Lagrangian trajectories are simulated using the method outlined in Visser (1997) but amended to take account of swimming behaviour. The Lagrangian-trajectory algorithms have also been shown to provide accurate approximations to the analytical solutions of some 1-dimensional testcases (Broekhuizen 1999). Similarly, although we have not performed formal statistical analysis of the types described in Brickman \& Smith (2002), inspection of 3-dimensional model results (using biologically inert, neutrally buoyant particles) indicates that local imbalances of particle concentration are temporary, probabilistic events rather than persistent features.

Forcing functions. Time-series (30 min resolution) of vertically resolved water temperature and current speeds are derived from a hydrodynamic model of New Zealand's NE shelf (Black et al. 2000) modified to include salinity effects associated with riverine inputs. We assume a horizontal dispersion coefficient of $10 \mathrm{~m}^{2}$ $\mathrm{s}^{-1}$ (derived by calibration of the hydrodynamic model). Instantaneous vertical dispersion rates are derived from the water-column depth and vertical shear, with a Richardson number correction for water-density gradients (Black et al. 2000). The resolution of the hydrodynamic model (5000 m horizontal, and progressively decreasing vertical resolution [from the sea-surface downward, layer thicknesses are: 2, 3, 5, 10, 20, 30, 50, $3 \times 100,3 \times 200,500,1000 \mathrm{~m}])$ also defines the spatial discretisation for our Eulerian variables (nutrients and organic detritus) and the finest resolution at which we will derive the statistical characteristics of the Lagrangian state variables.

Surface irradiance is simulated following Kirk (1983) with a cloud cover correction (Vincent et al. 1989). The photosynthetically active light is split into 2 components: 'red' - strongly absorbed by water; and 'green' weakly absorbed (Taylor et al. 1991). In addition to attenuation by water, we include phytoplankton dependent attenuation.

We make a $60 \mathrm{~d}$ simulation, with a nominal start date of October 1 (mid-spring). During the first $40 \mathrm{~d}$ of simulation, we apply alternating periods NW-wind driven currents (4 tidal cycles, $5 \mathrm{~m} \mathrm{~s}^{-1}$ wind-speed) and SEwind driven currents ( 2 tidal cycles, $5 \mathrm{~m} \mathrm{~s}^{-1}$ windspeed). For the latter $20 \mathrm{~d}$ of the simulation, the respective durations of the NW- and SE-winds are reversed. This pattern is not representative of any specific historical period, but is adopted as a simple means of reproducing the spring (prevailing NW winds and consequent upwelling conditions) and summer (frequent SE winds, and associated loss of upwelling).

Initial and boundary conditions. Table 1 lists our initial conditions-also applied as the horizontal boundary conditions - and Table 2 lists the parameters governing the model's description of biological processes. We assume all phytoplankton are in the upward swimming state, as dictated by both their $\mathrm{N}$ and Si quotas. The phytoplankton cells are assumed to have an initial $\mathrm{C}$ weight of $0.75 W_{\text {fission, }}$ and an $\mathrm{N}$ :C $(\mathrm{Si}: \mathrm{C})$ ratio of $0.5\left(Q_{\min }+Q_{\max }\right)$, where $Q_{\min }$ and $Q_{\max }$ denote the respective nominal minimum and maximum N (Si) cellular quotas.

Oceanic horizontal boundary conditions are imposed by including an extra strip of control-volumes along the outer NW, NE and SE walls of the domain. The prescribed boundary-condition values are applied within these 'boundary-strip' volumes.

For the phytoplankton, boundary conditions were specified by inserting the appropriate number (see below) of ensembles within each control-volume of the boundary-strip, and allowing them to evolve (grow, move horizontally). After each time-step, the number of ensembles within in each boundary-strip controlvolume is counted. If there are too many, the excess 
Table 1. Initial and boundary conditions. DIC: dissolved inorganic carbon; DIN: dissolved inorganic nitrogen; DRSi: dissolved reactive silicon. Mixed layer is ca. $60 \mathrm{~m}$ deep

\begin{tabular}{|lccc|}
\hline Variable & & $\begin{array}{c}\text { Within } \\
\text { mixed layer }\end{array}$ & $\begin{array}{c}\text { Below } \\
\text { mixed layer }\end{array}$ \\
\hline Net DIC & $\mathrm{mg} \mathrm{C} \mathrm{m}^{-3}$ & 0 & 0 \\
DIN & $\mathrm{mg} \mathrm{N} \mathrm{m}^{-3}$ & 10 & 100 \\
DRSi & $\mathrm{mg} \mathrm{Si} \mathrm{m}^{-3}$ & 60 & 110 \\
Detrital C & $\mathrm{mg} \mathrm{C} \mathrm{m}^{-3}$ & 1520 & 1520 \\
Detrital N & $\mathrm{mg} \mathrm{m} \mathrm{m}^{-3}$ & 205 & 205 \\
Detrital Si & $\mathrm{mg} \mathrm{Si} \mathrm{m}^{-3}$ & 334 & 334 \\
Diatom cells & cells m$^{-3}$ & $3 \times 10^{8}$ & 0 \\
Dinoflagellate cells & cells m & \\
& & $3 \times 10^{8}$ & 0 \\
\hline
\end{tabular}

(randomly selected) ensembles are deleted. If there are too few, the appropriate number of additional ensembles is added (at random locations within the controlvolume).

Each newly created Lagrangian Ensemble is representative of a user-defined number of cells. We have chosen the ensemble size such that within the surface layer of each water-column, there are initially 3 ensembles per meter of depth; deeper in the watercolumn, initial and boundary condition phytoplankton concentrations may be lower, in which case there are fewer ensembles per vertical meter. Within the entire domain, we carry approximately 210000 ensembles for

Table 2. Parameter values for the model. A mathematical description of the 1-dimensional biological model is presented in Broekhuizen (1999). DRSi: dissolved reactive silicon; DIN: dissolved inorganic nitrogen

\begin{tabular}{|c|c|c|c|c|}
\hline Parameter description & Units & Diatoms & Dinoflagellate & Comment \\
\hline $\begin{array}{l}\text { Background light attenuation coefficient } \\
\text { (red light) }\end{array}$ & $\mathrm{m}^{-1}$ & & & 0.4 (Taylor et al. 1991) \\
\hline $\begin{array}{l}\text { Background light attenuation coefficient } \\
\text { (green light) }\end{array}$ & & & & 0.08 (Taylor et al. 1991) \\
\hline $\begin{array}{l}\text { Phytoplankton-C-dependent light } \\
\text { attenuation coefficient (red and green) }\end{array}$ & $\mathrm{m}^{2} \mathrm{mg}^{-1} \mathrm{C}$ & 0.0004 & 0.0002 & (Chan 1980, Taylor et al. 1991) \\
\hline Detrital sinking speed & $\mathrm{m} \mathrm{d}^{-1}$ & & & 3 (Smayda 1970) \\
\hline Sinking speed & $\mathrm{m} \mathrm{d}^{-1}$ & 3 & 3 & $\begin{array}{l}\text { (Smayda 1970, Passow 1991, } \\
\text { Kamykowski et al. 1992, Waite } \\
\text { et al. 1992) }\end{array}$ \\
\hline 'Swim' speed & $\mathrm{m} \mathrm{d}^{-1}$ & 3 & 15 & $\begin{array}{l}\text { (Passow 1991, Kamykowski } \\
\text { et al. 1992, Waite et al. 1992) }\end{array}$ \\
\hline Cell weight at fission & $\mathrm{mg} \mathrm{C}$ cell $^{-1}$ & $675 \times 10^{-9}$ & $675 \times 10^{-9}$ & $\begin{array}{l}\text { Cell dimensions from H. Chang } \\
\text { (NIWA), weight relationships: } \\
\text { (Strathman 1967, Verity et al. } \\
\text { 1992) }\end{array}$ \\
\hline Cell weight at starvation-death & $\mathrm{mgC} \mathrm{cell}^{-1}$ & $270 \times 10^{-9}$ & $270 \times 10^{-9}$ & Assumed \\
\hline Max N:C ratio $\left(Q_{\max }\right)$ & $\mathrm{mgN} \mathrm{mg}^{-1} \mathrm{C}$ & 0.22 & 0.15 & (EPA 1985, Tett \& Droop 1988) \\
\hline Min. N:C ratio $\left(Q_{\min }\right)$ & $\mathrm{mgN} \mathrm{mg}^{-1} \mathrm{C}$ & 0.05 & 0.05 & (EPA 1985, Tett \& Droop 1988) \\
\hline Max Si:C ratio & $\mathrm{mgSi} \mathrm{mg}^{-1} \mathrm{C}$ & 0.30 & - & (Brzezinski 1985) \\
\hline Min $\mathrm{Si}$ C ratio & $\mathrm{mgSi} \mathrm{mg}^{-1} \mathrm{C}$ & 0.14 & - & (Brzezinski 1985) \\
\hline $\begin{array}{l}\mathrm{N} \text { or Si quotas at which cells commence } \\
\text { downward 'swimming' }\end{array}$ & $\mathrm{mg} \mathrm{mg}^{-1} \mathrm{C}$ & $\begin{array}{c}0.25 \times \\
\left(Q_{\max }+Q_{\min }\right)\end{array}$ & $\begin{array}{c}0.25 \times \\
\left(Q_{\max }+Q_{\min }\right)\end{array}$ & Assumed \\
\hline $\begin{array}{l}\mathrm{N} \text { or Si quotas at which cells re-commence } \\
\text { upward 'swimming' }\end{array}$ & $\mathrm{mg} \mathrm{mg}^{-1} \mathrm{C}$ & $\begin{array}{c}0.75 \times \\
\left(Q_{\max }+Q_{\min }\right)\end{array}$ & $\begin{array}{c}0.75 \times \\
\left(Q_{\max }+Q_{\min }\right)\end{array}$ & Assumed \\
\hline Half-saturation constant for DIN uptake & $\mathrm{mgN} \mathrm{m}^{-3}$ & 3 & 3 & $\begin{array}{l}\text { (Eppley et al. 1970, Caperon \& } \\
\text { Meyer 1972) }\end{array}$ \\
\hline Half-saturation constant for DRSi uptake & $\mathrm{mgSi} \mathrm{m}^{-3}$ & 30 & - & $\begin{array}{l}\text { (Paasche 1973, Nelson \& } \\
\text { Tréguer 1992) }\end{array}$ \\
\hline Half-saturation light intensity & $\mu E \mathrm{~m}^{-2} \mathrm{~s}^{-1}$ & 62.5 & 40 & (Chan 1980) \\
\hline Max. DIN-uptake rate & $\mathrm{ngN} \mathrm{mg}{ }^{-1} \mathrm{C} \mathrm{d}^{-1}$ & 0.5 & 0.3 & (Tett \& Droop 1988) \\
\hline Max. DRSi uptake rate & $n g$ Si mg ${ }^{-1} \mathrm{C} \mathrm{d}^{-1}$ & 0.4 & - & (Tett \& Droop 1988) \\
\hline Max. photosynthetic rate & $\mathrm{ngC} \mathrm{mg}^{-1} \mathrm{C} \mathrm{d}^{-1}$ & 2.5 & 1.2 & (Chan 1980) \\
\hline Basal respiratory rate & $\mathrm{ngC} \mathrm{mg}^{-1} \mathrm{C} \mathrm{d}^{-1}$ & 0.025 & 0.13 & (Langdon 1993) \\
\hline Daytime activity respiration & - & 0.13 & 0.2 & (Langdon 1993) \\
\hline Nighttime activity respiration & - & 0.065 & 0.2 & (Langdon 1993) \\
\hline Max (quota-dependent) $\mathrm{N}$ excretion rate & $\mathrm{ngN} \mathrm{mg}{ }^{-1} \mathrm{C} \mathrm{d}^{-1}$ & 0.1 & 0.1 & Assumed \\
\hline Max (quota-dependent) Si excretion rate & ng Si mg ${ }^{-1} \mathrm{C} \mathrm{d}^{-1}$ & 0.1 & - & Assumed \\
\hline \multicolumn{5}{|l|}{$\begin{array}{l}\text { Curvature-factor in sigmoidal (comple- } \\
\text { mentary-sigmoidal) functions governing } \\
\text { quota dependence of photosynthesis }\end{array}$} \\
\hline and nutrient excretion (nutrient uptake) & - & 20 & 20 & Assumed \\
\hline First-order background mortality rate & $d^{-1}$ & 0.1 & 0.02 & Assumed \\
\hline \multicolumn{5}{|l|}{ Temperature to which photosynthetic rates are } \\
\hline normalised & ${ }^{\circ} \mathrm{C}$ & 20 & 20 & \\
\hline Temperature to which respiratory rates are normalisec & ${ }^{\circ} \mathrm{C}$ & 15 & 15 & \\
\hline$Q_{10}$ for physiological rates & - & 2 & 2 & \\
\hline
\end{tabular}


each of the 2 classes of phytoplankton (cf. 5000 wetted Eulerian control-volumes). Preliminary trials indicated that this was sufficient to provide robust timeseries of local and domain-wide characteristics. For example, in comparison with simulations in which only 0.5 ensembles per vertical meter of the surface layer were carried (cf. 3), the simulated domain-wide standing stocks and cumulative production differed by $\ll 1 \%$ after 60 d. Similarly, the latter simulation yields almost indistinguishable moving average time-series of local diatom and dinoflagellate abundances. Inevitably, the low particle count simulation exhibited greater high frequency local-scale variability as a result of 'sampling error' effects (U-1 errors in the terminology of Brickman \& Smith 2002).

Point source inputs of nutrients (riverine and sewage discharges) are included for the Piako, Waiou and Kaueranga rivers together with Orewa, Army Bay and North Shore sewage plants (Fig. 1). Riverine nutrient data are supplied as monthly flow-weighted averages (Close \& Davies 1990, Vant 1999), whilst the sewage data stem from Regional Council records. Instantaneous values are derived from the monthly records by linear interpolation.

\section{RESULTS}

Fig. 2 illustrates the depth-averaged (0 to $20 \mathrm{~m}$ ) concentrations of nutrients and phytoplankton predicted by the B\#-LE variant of the model. Over the first $\sim 10 \mathrm{~d}$ of the simulation, concentrations of surface layer DRSi and to an even greater extent, DIN, become increasingly depleted over much of the domain. The B\#-LAE and BO-LAE model variants predict somewhat greater nutrient depletion than do their LE-analogues (not shown). Subsequently, the concentrations of both tend to rise. Depletion is less severe, and recovery more rapid in the upwelling areas (notably around Cape Rodney and east of the Colville Channel) and deep within the Firth of Thames (high nutrient loads from the rivers). After Day 40 of the simulation, the winds switch from prevailing northwesterlies to prevailing southeasterlies. This reduces the quantities and spatial extent of nutrient upwelling into the coastal surface water.

Initially, the diatom population grows rapidly, but as DIN becomes limiting over much of the domain, the diatom population begins to decline. Later, DIN levels in the Hauraki Gulf recover (reaching unrealistically high concentrations), but the diatom population continues to be held in check by Si-limitation. Surface ( 0 to $20 \mathrm{~m}$ ) dinoflagellate populations rise dramatically over the first few days of the simulation; however, most of this increase can be attributed to aggregation of much of the population (initially assumed to be evenly distributed over the top $60 \mathrm{~m}$ of the water-column) into the top $\sim 20 \mathrm{~m}$. In this top $20 \mathrm{~m}$, dinoflagellate population concentrations are predicted to exceed diatom concentrations for much of the simulation period. This is particularly marked within the Hauraki Gulf and Firth of Thames. Relative to diatoms, the dinoflagellate population tends to be a little further offshore during the period of prevailing NW winds, and much more inshore during the period of prevailing SE winds. Unlike the diatom concentrations, dinoflagellate concentrations are a little lower immediately above the upwelling areas than they are elsewhere. Dinoflagellates become extremely rare in the lee (NNW) of the Coromandel Peninsula and Great Barrier Island during prevailing SE winds.

Fig. 3 illustrates the corresponding coefficients of variation $(\mathrm{CV}=\mathrm{SD} / \mathrm{mean})$ for the cellular characteristics of diatoms and dinoflagellates. The CVs of diatom cell $\mathrm{C}$ weight rise rapidly over the first few days of the simulation, but stabilises at an average of $\sim 0.2$ by Day 15. The CV of dinoflagellate cell $\mathrm{C}$ weight rises more slowly, but has also stabilised at $\sim 0.2$ by Day 15 . In the case of dinoflagellates, the CV of cell weight shows some tendency to be a little larger in inshore areas. Initially, the $\mathrm{CV}$ of diatom $\mathrm{N}$ quota rises rapidly, being $\sim 0.4$ over much of the domain on Day 3 ; however, over most of the domain, it declines thereafter. Residual areas of high N quota CV (notably at the boundary between the Firth of Thames and the Hauraki Gulf, and along the NE edge of the model's domain) are associated with steep horizontal gradients of DIN. The CV of diatom Si quota rises more slowly than that of the $\mathrm{N}$ quota, and maximum variability is not attained until $\sim$ Day 10 . The domain-wide maximum CVs of Si quota are less than those of $\mathrm{N}$ quota, but in inshore areas, the CVs of $\mathrm{Si}$ quota tend to be greater than those of $\mathrm{N}$ quota. In particular, they remain substantial over the areas of upwelling in the open waters of the NE shelf. As with diatom $\mathrm{N}$ quota, diatom $\mathrm{Si}$ quotas tend to be most variable in areas of intermediate DRSi concentration associated with areas of steep DRSi gradients.

Fig. 4 illustrates the relative differences between the B\#-LE simulated distributions of diatoms and dinoflagellates and those simulated using the B\#-LAE variant. Later in the simulation, the latter model tends to predict lower inshore diatom cellular abundances. For dinoflagellates, the differences are less marked, but very close to the shore, the latter variant shows some tendency to predict higher dinoflagellate concentrations than the former. The patterns for population biomass are similar. Thus, the differences indicate differing levels of net production rather than a persistent tendency of the LAE variant of the model to predict fewer, but larger, cells than the LE variant. 
(a) DIN
(b) DRSi

(c) Diatoms

(d) Dinoflagellates
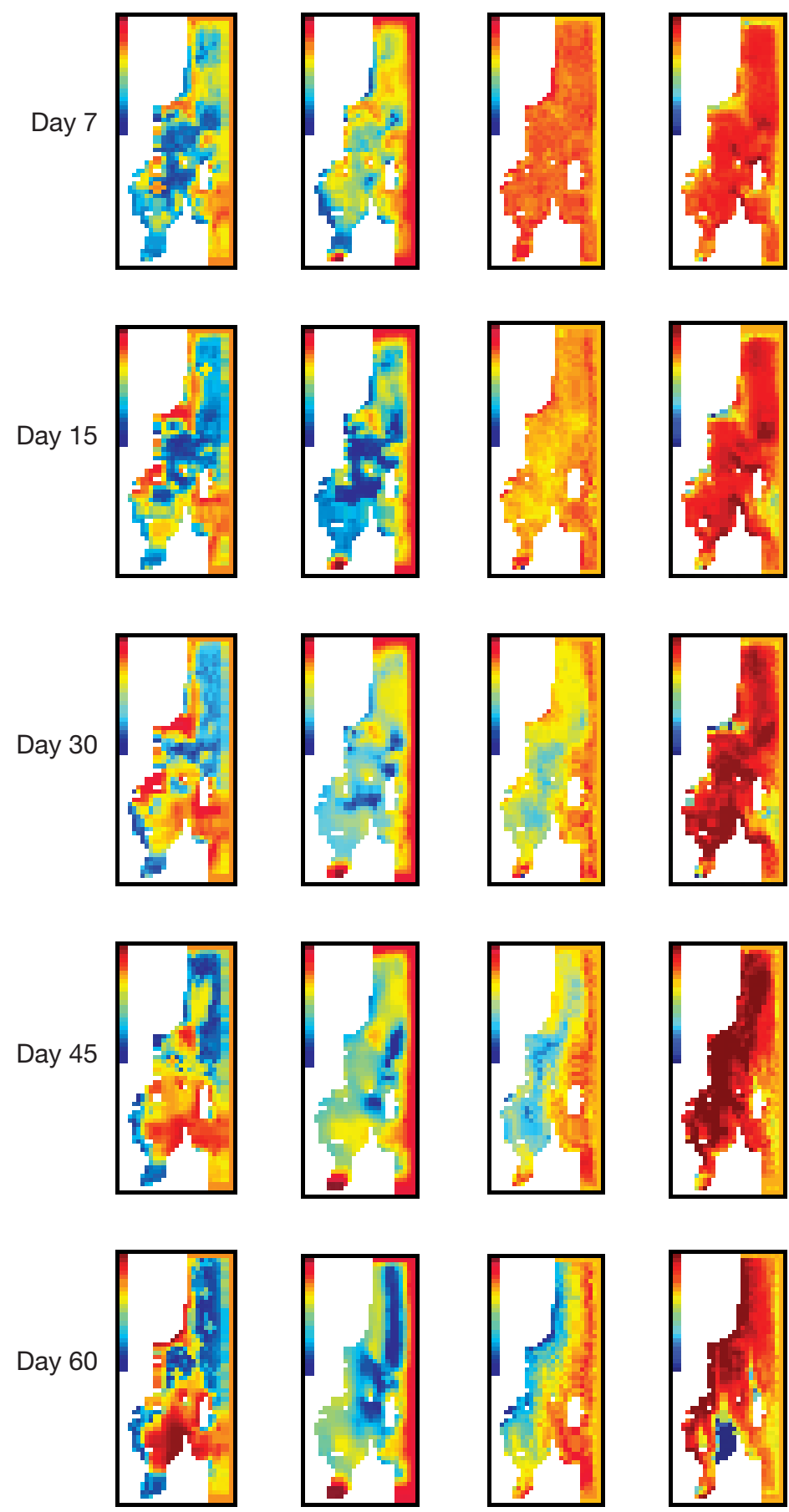

Fig. 2. Concentrations of (a) dissolved inorganic nitrogen (DIN, $\mathrm{mgN} \mathrm{m}{ }^{-3}$ ), (b) dissolved reactive silicon (DRSi, $\mathrm{mgSi} \mathrm{m}^{-3}$ ), (c) diatoms (cells $\mathrm{m}^{-3}$ ) and (d) dinoflagellates (cells $\mathrm{m}^{-3}$ ) averaged over the top $20 \mathrm{~m}$ of the water column as predicted by the biomass-andnumbers Lagrangian Ensemble (B\#-LE) variant of the model. The false-colour coding is proportional to $\log _{10}$ (concentration). Colour scales (top left of each plot) run (blue to brown) from -2 to $+2\left(\log _{10}\right.$ mgelement $\left.\mathrm{m}^{-3}\right)$ for DIN and DRSi, and from +6 to $+9.5\left(\log _{10}\right.$ cells $\mathrm{m}^{-3}$ ) for diatoms and dinoflagellates. Top to bottom, the panels correspond to Days $7,15,30,45$ and 60 from the start of the simulation
In Fig. 5a, we plot the time-series of cumulative diatom production within the domain. The diatom population grows rapidly for the first $5 \mathrm{~d}$ of the simulation, but growth slows thereafter. Initially, the dinoflagellate population grows slowly, however, its growth rate accelerates after the first 5 to $10 \mathrm{~d}$ of the simulation (Fig. 5b). Ultimately, the cumulative dinoflagellate production is predicted to exceed that of the diatoms by $\sim 30 \%$. Neither population shows a strong growth rate response when the winds switch from prevailing NW to prevailing SE at Day of Year 310. Dinoflagellates begin to die of starvation sooner than the diatoms and ultimately, the former group lose more than twice as many cells to this cause (Fig. 5c,d). For both taxa, the B\#-LE model predicts higher domain-wide standing stocks (Fig. 5e,f) than does the B\#-LAE variant; however, most of the divergence takes place over the first few days of the simulation when population growth is most rapid. Subsequently, they begin to converge once more. In the case of the dinoflagellates, this convergence becomes more rapid after Day of Year 310 when winds become prevailing southeasterly. By the end of the simulation, cumulative production predicted by the B\#-LAE variant amounts to $\sim 80 \%$ of that predicted by the B\#-LE variant. Cumulative dinoflagellate production predicted by the B\#-LAE model amounts to only $\sim 60 \%$ of that predicted by the B\#-LE model. At worst, the cell abundances predicted by the B\#-LAE variant can be $<50 \%$ of those predicted by the B\#-LE variant, although 70 to $90 \%$ is a more typical ratio.

The spatio-temporal dynamics predicted by the BO variants of the model are qualitatively similar to those already described for the biomass-andnumbers variants $(\mathrm{B} \#)$; however, there are some quantitative differences. In the case of the dinoflagellates, both BO variants of the model yield production and starvation mortality rates which are substantially greater than those yielded by the B\# variants; however, the resultant standing crops are intermediate between the predictions of the 2 B\# variants. The LE and LAE variants of the BO model yield almost identical estimates of production and starvation mortality. In the case of the diatoms, the BO-LAE variant yields higher production, starvation mortality and standing crop than the BO-LE variant, and both variants of the B\# model. The BO-LE variant yields a production rate which is very similar to that of the B\#-LE variant, but the predicted standing stock is more like that predicted by the B\#-LAE variant. 
(a) Diatom cell weight
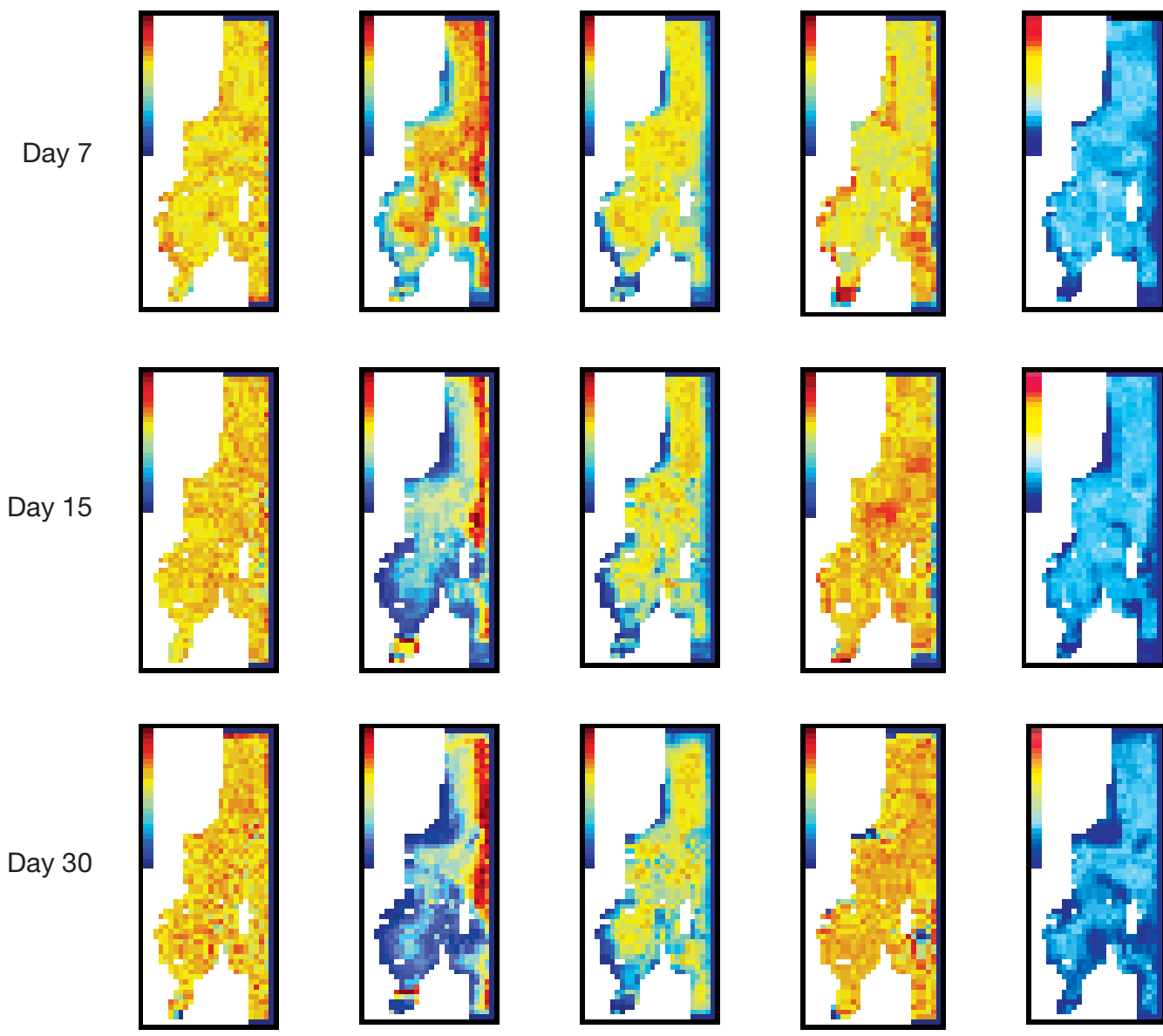

Day 45
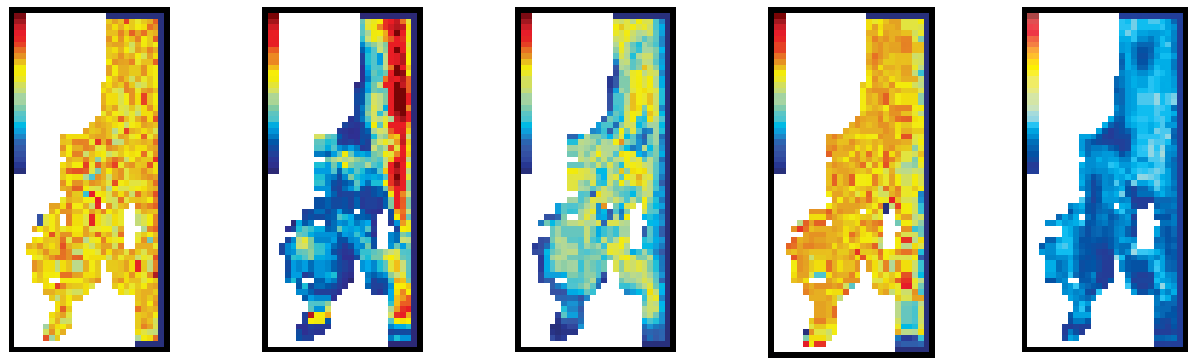

Day 60
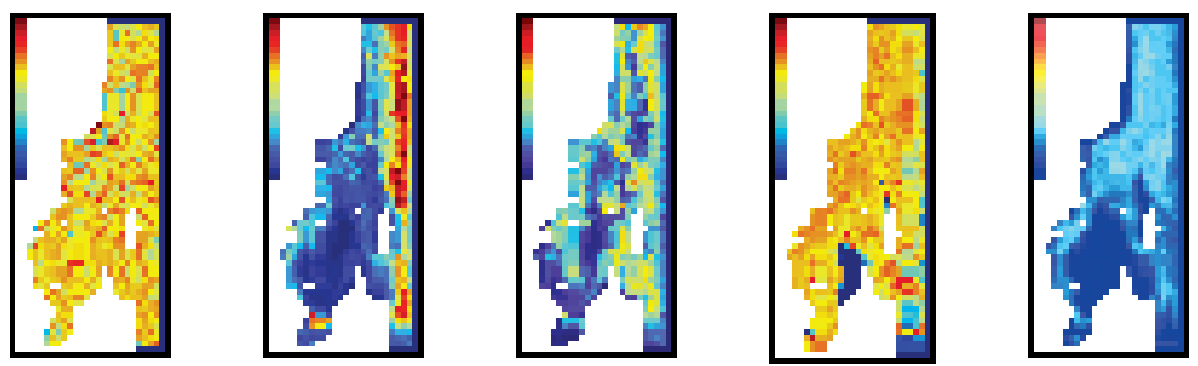

Fig. 3. Coefficients of variation (CV) for (a) diatom cell weight, (b) diatom cellular N quota, (c) diatom cellular Si quota, (d) dinoflagellate cell weight and (e) dinoflagellate cellular N quota. The colour scale runs (blue to brown) from 0 to 0.3 for the CVs of cell weights, and 0 to 0.5 for the CVs of cell quotas. Top to bottom, the panels correspond to Days $7,15,30,45$ and 60 from the start of the simulation 
Cellular abundance

(a) Diatoms

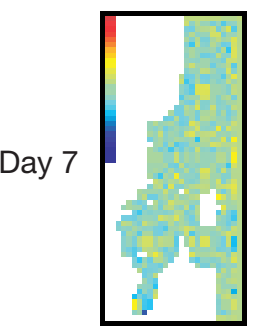

(b) Dinoflagellates

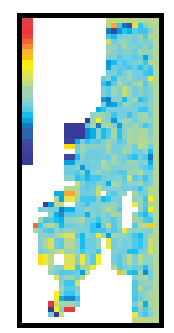

Population $\mathrm{C}$ biomass

(c) Diatoms

(d) Dinoflagellates
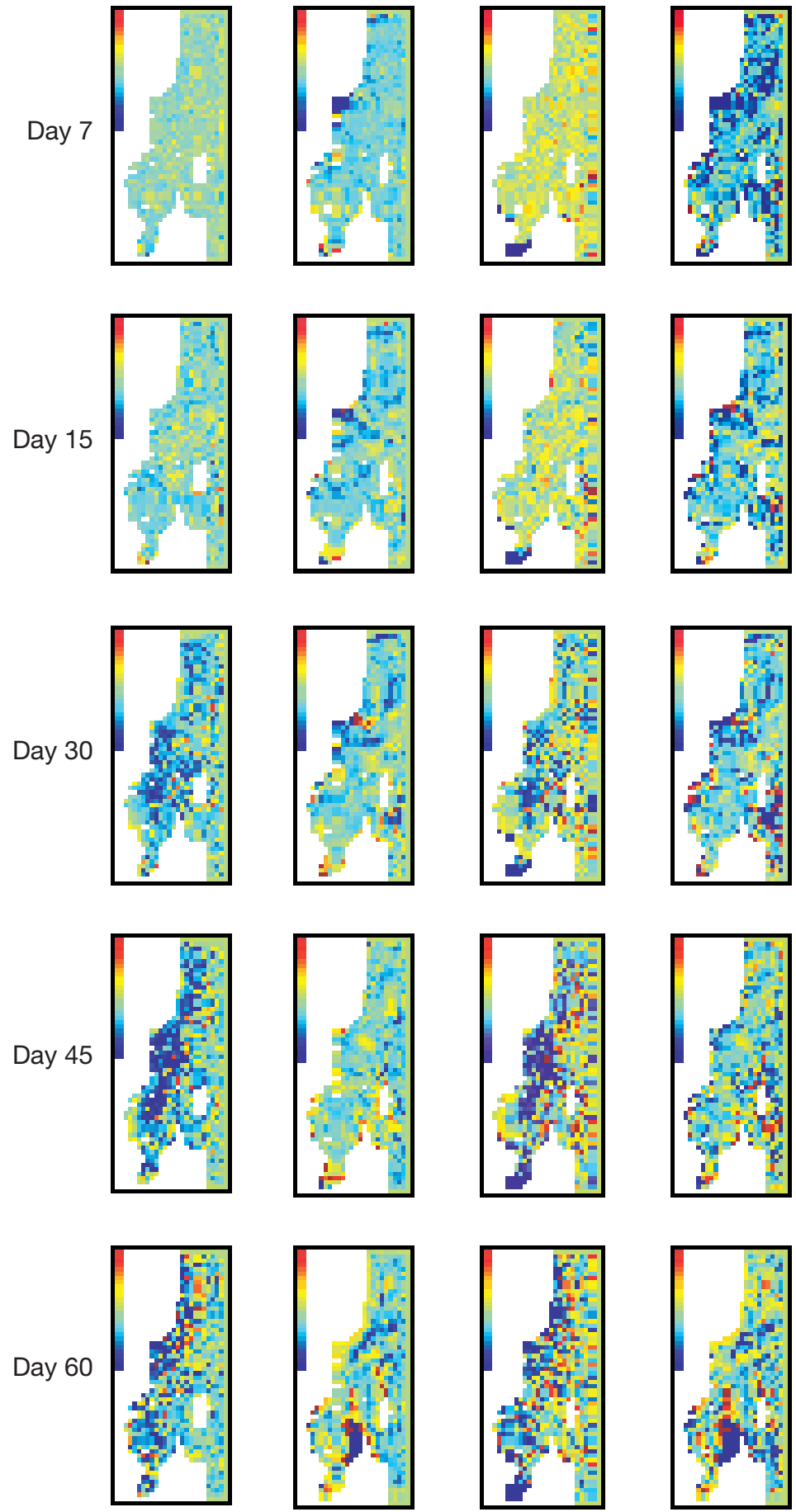

Fig. 4. Logarithmic (base 10) ratio (B\#-LAE/B\#-LE) of cellular abundance of (a) diatoms and (b) dinoflagellates, and population $\mathrm{C}$ biomass of (c) diatoms and (d) dinoflagellates simulated using the biomass-andnumbers Lagrangian Ensemble (B\#-LE) and biomass-and-numbers Lagrangian-as-Eulerian (B\#-LAE) variants. Cell abundance and C biomasses are averages over the top $20 \mathrm{~m}$. The colour scale runs (blue to brown) from $\log _{10}(0.25)$ to $\log _{10}(4)$. Ratios of less than 1 indicate that the concentrations predicted by the LE model exceed those predicted by the LAE one and vice versa. Top to bottom, the panels correspond to Days $7,15,30,45$ and 60 from the start of the simulation

\section{DISCUSSION}

Our primary aim is not to make a detailed comparison between simulation results and field data; however, we start by noting the qualitative agreement between the results of our Lagrangian model and field observations. For example, under upwelling conditions, the model reproduces the pattern of declining diatom abundance along a transect from the open shelf into the Hauraki Gulf and Firth of Thames. Similarly, during downwelling periods, it reproduces the decline of diatoms relative to dinoflagellates on the open shelf. The model also reproduces the substantial 'plume' of riverine DRSi which extends out from the Firth of Thames, and early in the simulation, the model correctly indicates the system to be N-limited; however, later in the simulation, DIN concentrations climb to implausibly high levels within the central and western Hauraki Gulf. We believe that 3 factors contribute to this failure of the model. Firstly, we suggest that DIN uptake by bacteria and photosynthetic nanoflagellates (absent in our model, but representing 10 to $50 \%$ of the phytoplankton biomass $>2 \mu \mathrm{m}$ during spring/early summer in the Hauraki Gulf) would help to absorb much of the regenerated N. Secondly, benthic denitrification rates are known to be substantial within this region (1.9 to $5.2 \mu \mathrm{M}$ $\mathrm{cm}^{-2} \mathrm{~s}^{-1}$, NIWA unpubl. data) and Giles (2001) estimated that, within the top 2 to $3 \mathrm{~cm}$ of the seafloor, denitrification rates were $\sim 14 \%$ of the rate of $\mathrm{N}$ remineralisation (see also Zeldis \& Smith 1999, J. Zeldis et al. unpubl.). Finally, we speculate that the rate at which water-column DRSi is replenished may be too low; our model does not include a benthic DRSi-efflux term and it is possible that our initial/boundary conditions for detritus-bound $\mathrm{Si}$ is too low. If DRSi replenishment is too slow, this may be the cause of the (false) tendency for the diatoms to become Si-limited and contribute to the excessive accrual of DIN.

Wind influences the abundance and distribution of both diatoms and dinoflagellates; however, the underlying mechanisms differ. In the case of diatoms, the influence is through windcontrolled upwelling of deep, nutrient-rich (but phytoplankton-poor) water, which stimulates diatom production (see also $\mathrm{H}$. Chang et al. unpubl.). Being motile, dinoflagellates are less dependent upon upwelled nutrients and the population tends to aggregate in the (relatively strongly stratified) surface waters, i.e. nutrientstressed individuals need to make only comparatively brief migrations below the nutricline in 
a)

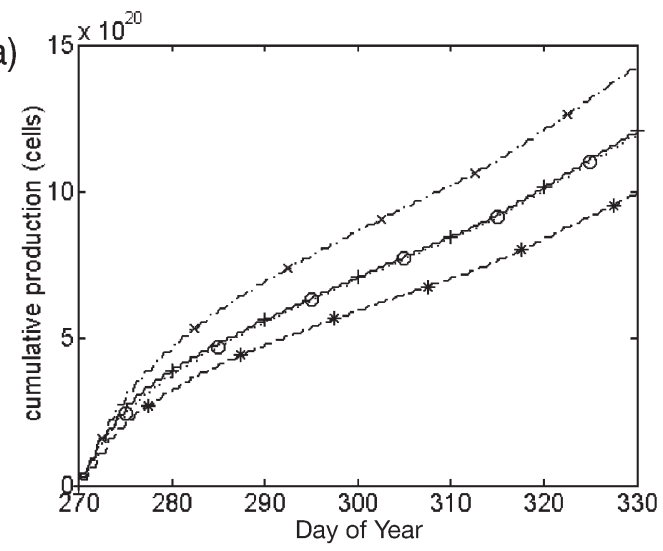

c)

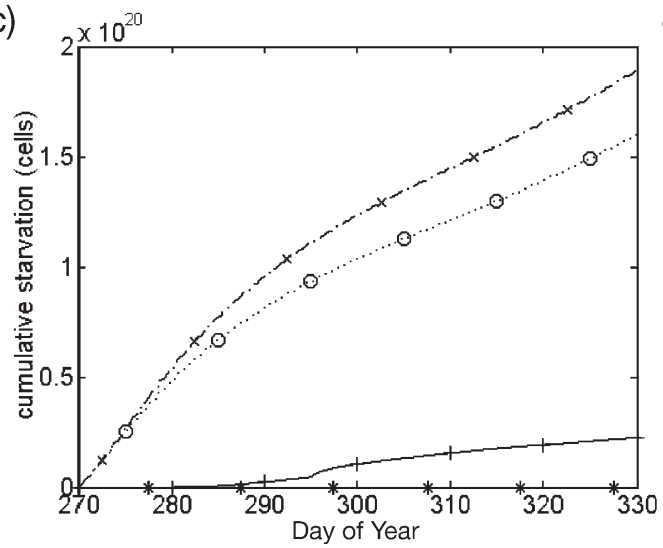

e)

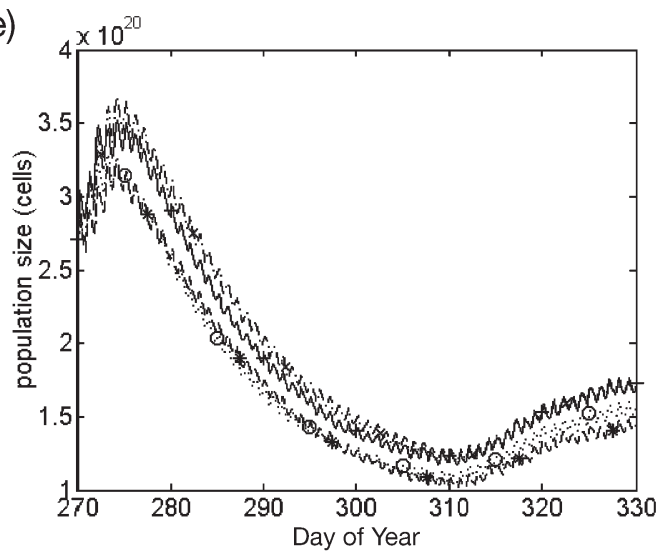

b)

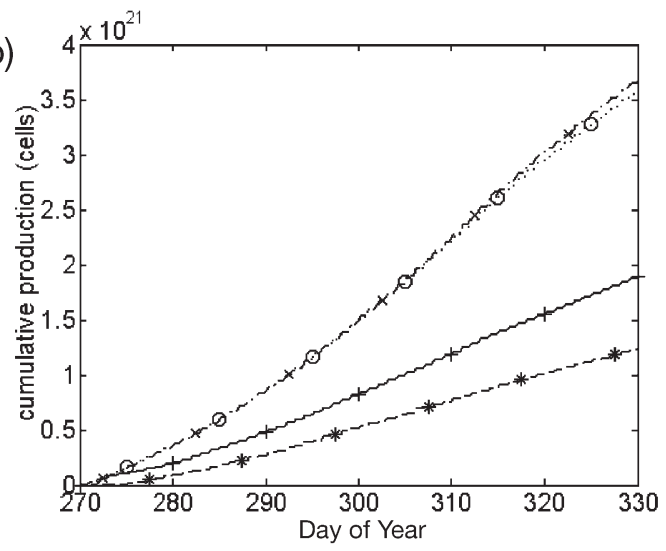

d)

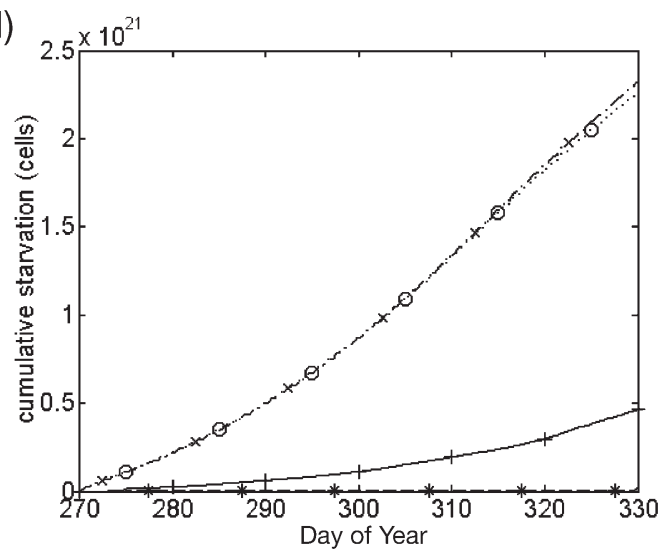

f)

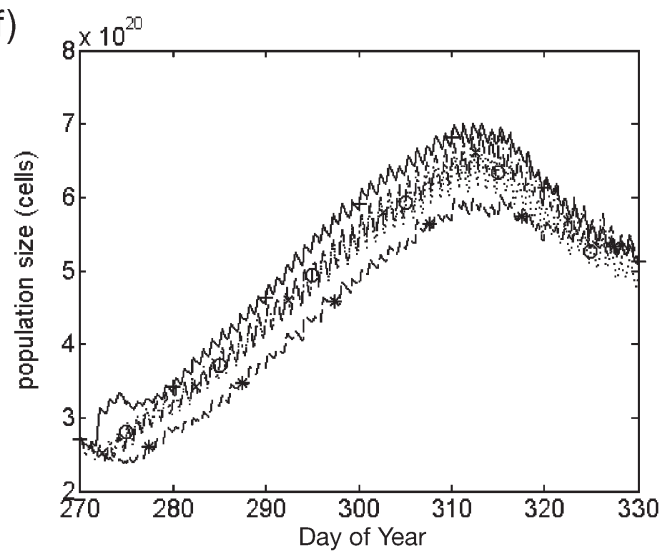

Fig. 5. (a,b) Cumulative production (cells); $(\mathrm{c}, \mathrm{d})$ cumulative cells lost to starvation; $(\mathrm{e}, \mathrm{f})$ total number of cells within domain; $(\mathrm{a}, \mathrm{c}, \mathrm{e})$ diatoms; (b,d,f) dinoflagellates. Solid-line and +: biomass-and-numbers Lagrangian Ensemble (B\#-LE) variant; dashed line and *: biomass-and-numbers Lagrangian-as-Eulerian (B\#-LAE) variant; dotted line and o: biomass-only Lagrangian Ensemble (BO-LE) variant; dash-dot line and $\times$ : biomass-only Lagrangian-as-Eulerian (BO-LAE) variant

order to replenish their nutrient stores. As a result of their greater aggregation within the surface waters and their comparatively low per-capita growth rates, wind-driven horizontal transport plays a much larger role in the local population dynamics of dinoflagellates than in the dynamics of diatoms. The comparative scarcity of dinoflagellates along the nearshore, open coastline during NW winds reflects the rapid offshore transport of these surface waters: horizontal dispersion combined with population growth appears to be insufficient to offset inshore losses arising from dilution by phytoplankton-poor deeper upwelled waters and offshore transport (see Speirs \& Gurney 2001).

We argue that the LAE approach provides a close approximation to a truly Eulerian formulation. Thus, although it is not prone to the inter-control-volume 
numerical dispersion that afflicts truly Eulerian formulations, it is still likely to yield erroneous results where individuals differ from one another at sub-grid-scale distances. We have shown that, within the top $20 \mathrm{~m}$ of the water-columns, both cell size and cell quota can show substantial variation (Fig. 3). Similar variations are evident at the scale of individual control-volumes. Although the Lagrangian and Lagrangian-as-Eulerian biomass-and-numbers variants of the model yield qualitatively similar phytoplankton dynamics, the latter variant frequently predicts abundances which are more than $10 \%$ lower, and often more than $30 \%$ lower, than those predicted by the former variant. Differences in the predicted turnover rate of the populations (production and starvation deaths) can be still higher. Comparison of the spatial distributions of the CVs of cell size and nutrient quota (Fig. 3) with the plots of the differences between abundance predicted by the Lagrangian and Lagrangian-as-Eulerian variants of the model (Fig. 4) provides some evidence that the Lagrangian and Lagragean-as-Eulerian prediction of standing stock are most dissimilar around the areas where the CVs are greatest. Thus, we conclude that there is little doubt that the Lagrangian and Lagrangian-as-Eulerian variants of the model yield differing results because of the combination of (1) false exchanges of cell properties (C, N, Si content) between phytoplankton within each controlvolume; and (2) the non-linearities governing cell growth and cell-fission or death.

Comparison of the results from B\# and BO variants suggests that, in the case of dinoflagellates, the non-linearity governing cell fission is most important in driving the differences which arose between the B\#-LE and B\#LAE results. In contrast, for the diatoms, the non-linear influence which cell quota has upon (1) photosynthesis (and nutrient uptake) and (2) 'swimming' direction appears to be dominant. This dichotomy is to be expected: the greater motility of the dinoflagellates enables them to regulate their $\mathrm{N}: \mathrm{C}$ ratio better than diatoms are able. The dinoflagellates maintain a high population-average $\mathrm{N}: \mathrm{C}$ ratio (results not shown), and there is little variation between ensembles (Fig. 3). The vast majority of dinoflagellates are swimming upward and occupying a part of the uptake-quota curve which is close to linear. In contrast, diatom nutrient quotas are frequently low (placing the ensembles in the non-linear part of the uptake-quota curve), and there is greater between ensemble variability. A simple graphical analysis shows that at low cell quotas (where the complementary-sigmoidal relationship between photosynthesis and nutrient quota has an ascending, concave form), the weight-specific photosynthetic and nutrient uptake rates inferred from the population average cell quota(s) will fall below true average rates (derived from the rates appropriate to each cell quota). This explains why the B\#-LE variants tend to yield higher production and standing stock than the B\#LAE ones, but not why the BO-LE variants yield lower production and standing stock than the BO-LAE ones.

The key difference between the B\# and BO formulations is that, in the latter, individual growth (net $\mathrm{C}$ accrual or loss) is instantaneously 'compounded' into population growth. This implies that, as measured by cell numbers, the $\mathrm{BO}$ variants yield faster day-time population growth and night-time population decline than do the B\# variants. This explains why the BO variants of the model exhibit larger diurnal fluctuations of abundance than do the B\# variants, but cannot alone explain why the B\#-LE variants predicts higher standing crops and turnover rates than the B\#-LAE variant, whilst the reverse pattern is evident in the BO variants. To explain this, we must consider the consequences of the (biologically spurious) betweenindividual exchanges of cellular properties which arise in the Lagrangian-as-Eulerian variants.

In the absence of this spurious exchange, individual cells which are deep in the water-column will tend to have a lower $\mathrm{C}$ weight than those closer to the surface; in the former case, the historical ratio of the rates of respiration to photosynthesis will be higher for most cells. Conversely, where there is any degree of nutrient-limitation in the surface waters, cells which are deep in the water column will tend to be richer in nutrients $(\mathrm{N}$ and $\mathrm{Si}$ ) than those close to the surface. Although less extreme, similar differences will also occur between the cells near the top and bottom of each control-volume. Thus, in the B\#-LAE variant, the false exchange of properties between all the residents within each control-volume (cf. numerical dispersion between control-volumes - which does not occur in our Lagrangian-as-Eulerian simulations) will tend to cause phytoplankton-associated $\mathrm{C}$ to diffuse downward, and phytoplankton-associated nutrient to diffuse upward through the water-column. When surface water nutrients are limiting, the spuriously rapid upward transfer of $\mathrm{N}$ (and $\mathrm{Si}$ ) allows the phytoplankton to fix more $C$ than would otherwise be the case. Similarly, the downward C-transfer enables the deep-water phytoplankton cells to incorporate more N (Si) than would otherwise be the case. In time, this nutrient may subsequently diffuse up to the surface. The enhanced deep-water uptake of nutrient and subsequent delivery to the surface explain why both the B\#-LAE and BO-LAE variants predict more extreme depletion of DIN and DRSi than do the strict Lagrangian variants. There is, however, another consequence of the spurious downward transport of $\mathrm{C}$ : slowed cell growth (and hence, population growth) in the surface waters. In the B\#-LAE variant of the model, this reduction in the near-surface population growth rate is not necessarily offset by a correspondingly enhanced growth rate 
deeper in the water-column. This is because, despite the spurious addition of $\mathrm{C}$ 'acquired' from above, the effective euphotic depth is increased only marginally, and much of the $\mathrm{C}$ which (falsely) diffuses to depth is lost to cells which are doomed to death-fromstarvation, rather than reproductive success. In the B\#-LAE variant of the model, the false, downward losses of $\mathrm{C}$ outweigh the increased $\mathrm{C}$ fixation which the false, upward transport of $\mathrm{N}$ and $\mathrm{Si}$ enables. Thus, the B\#-LAE variant predicts lower production and standing stock than does the B\#-LE variant.

Why is the same pattern not also evident in the BO variants? The reason is that, although the BO-LAE variant also tends to generate a false upward transport of nutrient and hence, greater near-surface $\mathrm{C}$ production, it does not generate any downward transport of $\mathrm{C}$. This is because we have formulated the BO model variants such that the notional cell-specific $\mathrm{C}$ content remains constant. Thus, there is no gradient of cellular C weights - either within or between control-volumes.

Simulations (not shown) support the preceding explanation: in the B\# variant, production and standing stock are suppressed (to a slightly greater extent than those of the B\#-LAE simulation) when cell C content (but not cell $\mathrm{N}$ and Si contents) are equilibrated across the member-ensembles of a control-volumes. Conversely, if cellular $\mathrm{N}$ and $\mathrm{Si}$ contents (but not C) are equilibrated, the simulated population production and standing stocks are a little greater than those predicted by the B\#-LE simulation. In the case of the BO model, corresponding simulations also indicate that equilibration of cellular $\mathrm{N}$ and $\mathrm{Si}$ (without accompanying $\mathrm{C}$ equilibration) yields slightly higher production and standing stock than is predicted by the BO-LE variant, whilst equilibration of cellular $\mathrm{C}$ (but not $\mathrm{N}$ and $\mathrm{Si}$ ) has no influence upon production and standing stock.

\section{CONCLUSIONS}

We have shown that under realistic environmental conditions, substantial sub-grid scale variability between individuals can arise. Like McGillicuddy (1995), we have found that the Lagrangian and Lagrangianas-Eulerian formulations yield estimates of daily phytoplankton production that differ by no more than a few percent, but our simulations suggest that these differences can accumulate and lead to differences in simulated standing crop and cumulative production of several 10s of percent in only a few days. Whilst we base this conclusion upon only the few Lagrangian Ensemble and Lagrangian-as-Eulerian simulations presented in this manuscript, we believe that they are more generally true: we have also made B\#-LE and truly simple-Eulerian (cf. Lagrangian-as-Eulerian) simulations with a variety of other wind scenarios. The truly Eulerian variant always yielded results which differ by 10 s of percent relative to the B\#-LE results.

We do not wish to imply that discrepancies of the magnitude which we have found between the predictions of our 4 model formulations are greater than those which might arise when using a single formulation, but instead, varying even a single parameter (or boundary condition) within the (typically broad) uncertainty limits. Furthermore, numerous Eulerian models have yielded good reproductions of field data. Nonetheless, because of their greater biological realism, it is probable that models which take explicit account of individual variability will be easier to fit to field data. They will probably also require less 'distortion' of the true-rate parameters. If so, this is likely to increase the likelihood that models developed in 1 area can be applied elsewhere without recalibration.

If it is deemed that it will be necessary to take account of between-individual differences at subspatial-grid scales, 3 methods present themselves: (1) the Lagrangian Ensemble method, (2) an extendedEulerian approach, and (3) a composite, discrete-time approach as presented by Gurney et al. (2001). The latter utilises a particle tracking approach to derive (spatial) transport properties in the form of a timeseries of spatial-grid-cell to spatial-grid-cell transition probabilities (redistribution kernel). Subsequently, an extended-Eulerian-like method is used to simulate the evolution of physiological properties within spatial-grid cells. Transport fluxes are incorporated into the evolution equations by means of discrete-time 'mixing' events which move individuals between (not necessarily adjacent) spatial boxes in the manner dictated by the previously derived transition probabilities.

The merits of the Lagrangian Ensemble approach lie in (1) its resistance to numerical error associated with calculating advective fluxes; (2) the intuitive appeal which it carries because of the close-correspondence between the model's formulation and the biological structure of the system; and (3) the ease with which additional biological detail can be added without greatly increasing the numerical intractability of the problem (i.e. although run-times may increase, the problem remains amenable to solution with relatively simple algorithms). The disadvantages of the method are 3-fold. Perhaps most fundamentally, the random-dispersion modelling approach used to derive the particle trajectories may be prone to failure when turbulence is spatially, highly inhomogenous and insufficiently resolved (Brickman \& Smith 2002, but see Visser 1997 for a discussion of at what location within the time-step the local dispersion coefficient should be calculated). Secondly, because the advective-velocity field is usually specified at discrete intervals (space and time), it will 
usually be necessary to derive a local-to-the-ensemble velocity - with the accompanying risk of approximation error. On a more practical basis, the Lagrangian Ensemble method is computationally very demanding.

Given the limitations of the Lagrangian Ensemble approach and the observation that the extended Eulerian approach requires no differential equations for rate of change of location, it might be thought that the extended Eulerian approach offers a superior solution. There are several situations in which this may not be the case. Firstly, there are circumstances in which the computational demand of the extended Eulerian approach is likely to be of the same order as that of the Lagrangian Ensemble method-notably where the total number of domain nodes (spatial and physiological axes) is large, but many of these will usually be devoid of individuals. Of course, if the modeller has some a priori knowledge and is prepared to sacrifice some generality, it may be possible to eliminate some of the empty nodes by adopting a specifically tailored discretisation scheme in place of a generic (e.g. 'square') one. A more fundamental limitation of the extended Eulerian approach relates back to the tendency for numerical dispersion to be produced when solving advective problems using a gridbased approach - whether the advection is along a spatial or a physiological axis. Broström (2002) demonstrated that biological amplification of the false (spatial) dispersion can swamp the true solution, even when advective schemes, which are less dispersive than the upwind method, are used. Similar considerations are also likely to apply in the case of false physiological dispersion. There is also another problem that may be of greater practical concern: by introducing physiological axes, the dimensionality of the advection problem is increased ( 3 spatial plus 1 or more physiological dimensions). In general, as the dimensionality of the advectionequations rise, the maximum permissible time-step declines. Furthermore, it can also become necessary to adopt more sophisticated algorithms to calculate the advective fluxes between nodes adequately. Both factors increase the computational burden of the problem.

The method proposed by Gurney et al. (2001) is less prone to numerical errors (in the spatial dimensions) than continuous-time Eulerian methods, and under some circumstances it can also eliminate numerical dispersion along the physiological axes. If repeated runs are to be made using the same (spatial) transport properties, e.g. during calibration or sensitivity exercises, it has the potential to yield results which are at least as accurate as those of the Lagrangian Ensemble method at a far lower computational cost per run. One disadvantage of this method is that the transportmatrix of transition probabilities must be calculated prior to running the biological model. This implies that, although the method is well suited to systems in which swimming is influenced by 1 or more of (1) primarily physically determined variables (temperature, salinity etc.); and (2) the organism's instantaneous physiological state. However, it would be more difficult to apply in situations where the organisms regulate their swimming behaviour in response to an external property which is itself influenced by the organism (as would be the case in a phytoplankton-zooplankton model in which grazer swimming is influenced by the local food concentration or concentration-gradient). A second disadvantage is that this method preserves only the second moment (variance) of dispersal distances. Under some circumstances the associated distortion of the higher moments of the dispersal kernel may influence the dynamics unduly (MacIsaac et al. 2002).

Theoretically, methods which incorporate a representation of local-scale individual variability should yield results which are more accurate than those which do not. This raises the question: given the greater computational burden of methods which incorporate localscale physiological variability, are the projected prediction errors associated with the simple-Eulerian method acceptable? There is no definitive answer to this question but we suggest that relative to the precision of shipboard estimates of abundance and production, a $10 \%$ error in simulation results might be considered acceptable, but it is unlikely that differences in excess of $30 \%$ could be considered so. Our simulations indicate that, in a physically realistic environment, it may not be uncommon for the differences between the predictions of a model incorporating individual variability, and a model that does not, to exceed $30 \%$.

Acknowledgements. This work is funded by the New Zealand Foundation for Research in Science \& Technology (contract \#CO1X0027). J. C. Rutherford and G. M. McBride along with 4 anonymous referees have provided valuable comments during the development of this manuscript. R. Gorman provided useful advice regarding details of the hydrodynamic model used to drive our biological model.

\section{LITERATURE CITED}

Barkmann W, Woods JD (1996) On using a Lagrangian model to calibrate primary production determined from in vitro incubation measurements. J Plankton Res 18:767-788

Black KP, Bell RG, Oldman JW, Carter CS, Hume TM (2000) Features of 3-dimensional barotropic and baroclinic circulation in the Hauraki Gulf, New Zealand. NZ J Mar Freshw Res 34:1-28

Brickman D, Smith PC (2002) Lagrangian stochastic modeling in coastal oceanography. J Atmos Ocean Technol 19: 83-99

Broekhuizen N (1999) Simulating motile algae using a mixed Eulerian-Lagrangian approach: does motility promote dinoflagellate persistence or co-existence with diatoms? J Plankton Res 21:1191-1216

Broström G (2002) On advection and diffusion of plankton in coarse resolution ocean models. J Mar Syst 35:99-110 
Brzezinski MA (1985) The Si:C:N ratio of marine diatoms: interspecific variability and the effect of some environmental variables. J Phycol 21:347-357

Caperon J, Meyer J (1972) Nitrogen-limited growth of marine phytoplankton. II. Uptake kinetics and their role in nutrient-limited growth of phytoplankton. Deep-Sea Res I 19: $619-632$

Chan AT (1980) Comparative physiological study of marine diatoms and dinoflagellates in relation to irradiance and cell size. II. Relationship between photosynthesis, growth, and carbon/chlorophyll a ratio. J Phycol 16:428-432

Chapra SC (1997) Surface water-quality modelling. McGrawHill, New York

Close ME, Davies CRJ (1990) Baseflow water chemistry in New Zealand rivers. 1. Characterisation. NZ J Mar Freshw Res 24:319-341

Enríquez S, Duarte CM, Sand-Jensen K (1993) Patterns in decomposition rates among photosynthetic organisms: the importance of detritus C:N:P content. Oecologia 94:457-471

EPA (Environmental Protection Agency) (1985) Algae. In: Bowie GL, Mills WB, Porcella DB, Campbell CL and 6 others (eds) Rates, constants, and formulations in surface water quality modelling, Chap 6. United States Environmental Protection Agency, Athens, GA, p 279-234

Eppley RW, Rogers JN, McCarthy JJ (1970) Half-saturation constants for uptake of nitrate and ammonium by marine phytoplankton. Limnol Oceanogr 14:912-920

Giles H (2001) Modelling denitrification in continental shelf sediments. Department of Biology, University of Waikato, Hamilton

Gurney WSC, Speirs DC, Wood SN, Clarke ED, Heath MR (2001) Simulating spatially and physiologically structured populations. J Anim Ecol 70:881-894

Hourdin F, Armengaud A (1999) The use of finite-volume methods for atmospheric advection of trace species. Part I. Test of various formulations in a general circulation model. Mon Weather Review 127:822-836

Janowitz GS, Kamykowski D (1999) An expanded Eulerian model of phytoplankton environmental response. Ecol Model 118:237-247

Kamatani A (1982) Dissolution rates of silica from diatoms decomposing at various temperatures. Mar Biol 68:91-96

Kamykowski D, Reed RE, Kirkpatrick GJ (1992) Comparison of sinking velocity, swimming velocity, rotation and path characteristics among 6 marine dinoflagellate species. Mar Biol 113:319-328

Kamykowski D, Yamazaki H, Janowitz GS (1994) A Lagrangian model of phytoplankton photosynthetic response in the upper mixed layer. J Plankton Res 16:1059-1069

Kara AB, Rochford PA, Hurlburt HE (2000) An optimal definition for the ocean mixed layer depth. J Geophys Res 105: 16803-16821

Kirk JTO (1983) Light and photosynthesis in aquatic ecosystems. Cambridge University Press, Cambridge

Langdon C (1993) The significance of respiration in production measurements based on oxygen. ICES Mar Sci Symp 197:69-78

Lizon F, Seuront L, Lagadeuc Y (1998) Photoadaptation and primary production study in tidally mixed coastal waters using a Lagrangian model. Mar Ecol Prog Ser 169:43-54

MacIsaac HJ, Robbins TC, Lewis MA (2002) Modelling ships bassast water as invasion threats to the Great Lakes. Can J Fish Aquat Sci 59:1245-1256

McGillicuddy DJJ (1995) One-dimensional numerical simulation of primary production: Lagrangian and Eulerian formulations. J Plankton Res 17:405-412
Nelson DM, Tréguer P (1992) Role of silicon as a limiting nutrient to Antarctic diatoms: evidence from kinetic studies in the Ross Sea ice-edge zone. Mar Ecol Prog Ser 80: 255-264

Paasche E (1973) Silicon and the ecology of marine plankton diatoms. III. Silicate-uptake kinetics in 5 diatom species. Mar Biol 19:262-269

Passow U (1991) Species specific sedimentation and sinking velocities in diatoms. Mar Biol 108:449-455

Smayda TJ (1970) The suspension and sinking of phytoplankton in the sea. Oceanogr Mar Biol Annu Rev 8:353-414

Smith EL (1936) Photosynthesis in relation to light and carbon dioxide. Proc Natl Acad Sci USA 22:504-511

Speirs DC, Gurney WSC (2001) Population persistence in rivers and estuaries. Ecology 82:1219-1237

Strathman RR (1967) Estimating the organic content of phytoplankton from cell volume or plasma volume. Limnol Oceanogr 12:411-418

Taylor AH, Watson AJ, Ainsworth M, Robertson JE, Turner DR (1991) A modelling investigation of the role of phytoplankton in the balance of carbon at the surface of the North Atlantic. Global Biogeochem Cycles 5:151-171

Tett P, Droop MR (1988) Cell quota models and planktonic primary production. In: Wimpenny JWT (ed) CRC handbook of laboratory model systems for microbial ecosystems, Vol II. CRC Press, Boca Raton, FL, p 177-233

Tréguer P, Kamatani A, Gueneley S, Quéguiner B (1989) Kinetics of dissolution of Antarctic diatom frustules and the biogeochemical cycle of silicon in the Southern Ocean. Polar Biol 9:397-403

van Leer B (1977) Towards the ultimate conservative difference scheme. IV. A new approach to numerical convection. J Comp Phys 23:276-299

Vant WN (1999) Sources of the nitrogen and phosphorus in several major rivers in the Waikato Region. Environment Waikato, Hamilton

Verity PG, Robertson CY, Tonzo CR, Andrews MG, Nelson JR, Sieracki ME (1992) Relationships between cell volume and the carbon and nitrogen content of marine photosynthetic nanoplankton. Limnol Oceanogr 37:1434-1446

Verity PG, Williams SC, Hong Y (2000) Formation, degradation, and mass:volume ratios of detritus derived from decaying phytoplankton. Mar Ecol Prog Ser 207:53-68

Villareal TA (1992) Buoyancy properties of the giant diatom Ethmodiscus. J Plankton Res 14:459-463

Vincent WF, Wake GC, Austin PC, Bradford JM (1989) Modelling the upper limit to oceanic phytoplankton production as a function of latitude in the New Zealand Exclusive Economic Zone. NZ J Mar Freshw Res 23:401-410

Visser AW (1997) Using random walk models to simulate the vertical distribution of particles in a turbulent water column. Mar Ecol Prog Ser 158:275-281

Waite AM, Thomson PA, Harrison PJ (1992) Does energy control the sinking rates of marine diatoms? Limnol Oceanogr 37:468-477

Woods JD, Barkmann W (1993) Diatom demography in winter-simulated by the Lagrangian Ensemble method. Fish Oceanogr 2:202-222

Woods JD, Onken R (1982) Diurnal variation and primary production in the ocean-preliminary results of a Lagrangian Ensemble model. J Plankton Res 4:735-756

Zeldis JR, Smith SV (1999) Water, salt and nutrient budgets for Hauraki Gulf, New Zealand. In: Smith SV, Crossland CJ (eds) Australasian estuarine systems: carbon, nitrogen and phosphorus fluxes. LOICZ Reports \& Studies, No. 12, LOIZ IPO, Texel

Submitted: August 16, 2002; Accepted: January 10, 2003

Proofs received from author(s): April 3, 2003 